\title{
EDITORIAL
}

\section{Medical Malpractice While My Guitar Gently Weeps}

After about a 20-year hiatus, I decided to start to play guitar again. I'm not sure if it is because of the new Beatles Rock Band game my son has for his Wii, out of boredom, or to offset the deafening ambient noise levels in my house. Both of my children are learning musical instruments; my son has a new trumpet, which prompted my daughter to bring home a flute or recorder (or whatever is called these days). Subconsciously, like any good parent, I think I wanted to inflict the same kind of ear-splitting torture on them that they put me through. The problem for me and my guitar is that if you create a Venn diagram of the songs I like, the songs I can actually play, and the songs that I can almost sing, the middle of the diagram consists of five songs total in the English language (and three are by Del Amitri). But like Carl Lewis singing the national anthem, I've never let minor details such as a complete lack of musical talent stop me. My wife recently postponed the kitchen remodel in favor of a soundproof room in the basement.

I like to learn new things. Although, or possibly because, I spend a great deal of my time teaching, it is easy to forget how daunting learning can be. Teaching procedural skills to fellows and residents may be more difficult than guitar. Academic interventional radiology is more akin to driving school-at some point, you have to let the kid take the wheel, and there is no blueprint on when and how to do this. It can be scary and mistakes are bound to be made. There were no driving instructors where I grew up. Therefore, I received lessons from my dad. Like most fathers and men in general, he approached driver's education like a foreman overseeing a group of workers who can't speak English. His commands generate puzzled looks punctuated by louder commands followed by vacant expressions. On an quiet abandoned road near a beach on the west side of Kauai, the only audible sounds during our lessons were seagulls and the muffled screams of profanity coming from my father in the suicide seat of his 1976 baby blue Cutlass Supreme.

Teaching procedural-based catheter skills is becoming increasingly difficult in the current medicolegal climate of Chicago. I'm convinced some patients and many lawyers view any unforeseen event as a potential winning lottery ticket. I was involved in a particularly painful malpractice case that was recently settled. My entire involvement consisted of interpreting a follow-up abdominal computed tomography (CT) scan on a Saturday for a woman who had recently undergone gastric bypass surgery. It showed the usual postoperative findings, which hadn't changed from the CT done 3 days earlier. The patient went home, recovered, and began eating. Unfortunately, 6 weeks later, she got sick again and returned to the emergency room with abdominal pain. She then left after 45 minutes, against medical advice and prior to being seen by a physician, and went home. She was called at home and urged to return to the hospital. She expired from a ruptured abdominal abscess at home the next day and a lawsuit was filed.

The crux of the malpractice case was my interpretation of her CT done 6 weeks earlier. You'll have to take my word that it did not show an abscess. Of course, in our wonderful legal system, it is not particularly difficult to find some medical "expert" who will pretty much say anything a plaintiff's attorney wants. The plaintiff's radiology expert claimed that there was a "developing abscess" that I had failed to diagnose, which caused the patient's tragic demise. I spent hours reviewing medical records from all aspects of this case, which are still on the floor in my office. When stacked up, they are nearly 3 feet high and easily weigh over 20 pounds. During my deposition, I was asked about my failure to diagnose the abscess... over and over and over again.

During the plaintiff's expert's deposition, it was quickly apparent that he was no expert. I assumed he was going to point to a random area of the upper abdomen and call it a "developing abscess." As it turns out, he didn't even understand the anatomy of a post-gastric bypass patient. He identified the excluded stomach, a normal finding, as an abscess. He said he had never heard of the term "excluded stomach." As my first foray into medical litigation, I was amazed. Who goes to a

\footnotetext{
${ }^{1}$ Section of Vascular and Interventional Radiology, University of Chicago Medical Center, Chicago, Illinois.

Address for correspondence and reprint requests: Brian Funaki, M.D., Section of Vascular and Interventional Radiology, University of Chicago Medical Center, 5840 S. Maryland Avenue, MC 2026, Chicago, IL 60637.

Trauma in Interventional Radiology; Guest Editor, Anthony D.
}

Goei, M.D., F.A.C.S.

Semin Intervent Radiol 2010;27:1-2. Copyright (C) 2010 by Thieme Medical Publishers, Inc., 333 Seventh Avenue, New York, NY 10001, USA. Tel: +1(212) 584-4662. DOI: http://dx.doi.org/10.1055/s-0030-1247883. ISSN 0739-9529. 
deposition as an expert radiologist and doesn't even know the anatomy of the patient?

I commented to my attorney that this guy should be suspended by the American College of Radiology (ACR). Funny thing was that my attorney called the ACR on a whim and discovered that the expert actually had been suspended by the ACR. What are the odds of that? He had committed "ethical violations during malpractice testimony." I thought that this discovery and the time course of the patient's illness pretty much sealed the deal in my favor. I thought wrong. My lawyer explained to me that the facts were more or less immaterial and I had to convince the jury that I was correct and the plaintiff's expert was wrong. It wasn't at all clear to me how to do that. As far as I could tell, this would be akin to holding up a hieroglyphic symbol in front of a jury that has no background in the language and having two "experts" argue about what the scribble really meant. Who were they supposed to believe? Moreover, in this case, the patient did ultimately have an abdominal abscess. Who would you believe under those circumstances?
In malpractice proceedings, it seems like the physician is pretty much guilty unless proven innocent. Ultimately, over 5 years after the case was filed, and after hours of depositions and case reviews, it was settled out of court on the eve of the trial date and I was (thankfully) dismissed from the suit. Perhaps the 1000 times I said that the scan failed to show an abscess was ultimately convincing enough. I don't know. I do know that it was a horrible experience, a tragic case, and I felt worst of all for the patient's family. No one really "wins" in these things.

I think one of the problems we have with malpractice litigation is that as physicians, we're trained to seek the truth. In a lawsuit, the truth is secondary to who can sell a story better. I'm not sure what this all means except that saying we need health care reform without tort reform is more laughable than my guitar skills.

Brian Funaki, M.D. ${ }^{1}$ Editor in Chief 